\title{
Hypercalcemia due to Nasopharyngeal Carcinoma
}

\author{
Shipra Chaudhary', Jeetendra Prasad Sah' \\ 'Department of Pediatrics \& Adolescent Medicine, BP Koirala Institute of Health Sciences, Dharan, Nepal.
}

\begin{abstract}
Hypercalcemia is a rare metabolic disorder associated with hyperparathyroidism, malignancy and various other causes. Although common in adult malignancies, hypercalcemia is rare in pediatrics and purports poor prognosis. Nasopharyngeal carcinoma is rare with no reported hypercalcemic presentation. We present here a case of hypercalcemia in a child of nasopharyngeal carcinoma. A 10 year girl presented with backache for 1 month, epistaxis, cough, chest-pain for 1 week alongwith anorexia and weight loss. Investigations revealed anemia and hypercalcemia $(23 \mathrm{mg} / \mathrm{dl}$; normal range $9-11 \mathrm{mg} / \mathrm{dl}$ ) with hyperphosphatemia, normal parathyroid levels. Hypercalcemic crisis was managed with saline, furosemide and bisphosphonate. Computed Tomography of paranasal sinuses revealed mass in right nasal cavity. Endoscopic biopsy disclosed undifferentiated nasopharyngeal carcinoma. The child expired despite supportive measures. Thus, hypercalcemia, though rare, may complicate advanced tumors. NPC, being rare in children, requires high index of suspicion with careful clinicoradiological examination and timely management for better chances of survival.
\end{abstract}

Keywords: Humoral hypercalcemia of malignancy (HHM); Hypercalcemia; Nasopharyngeal carcinoma (NPC).

\section{INTRODUCTION}

Hypercalcemia is an uncommon dyselectrolytemia associated with hyperparathyroidism, malignancy, medications, tuberculosis, etc. ${ }^{1}$

Hypercalcemia of malignancy, a paraneoplastic condition, is frequent in adults $(10-40 \%)$ but rare 10.4 $0.7 \%$ ) in children. ${ }^{2,3}$ It usually occurs in cancer lung, breast, ovary, kidneys; multiple myeloma; squamous cell carcinoma of head/neck; adult T-cell leukemia and lymphoma and often purports a poor prognosis. ${ }^{3-5}$

Amongst pediatric tumors, nasopharyngeal carcinoma (NPC) is a rare entity. ${ }^{6}$ Here we describe the course of a child presenting with serum calcium $23 \mathrm{mg} / \mathrm{dl}$ (normal, 9 $-11 \mathrm{mg} / \mathrm{dl}$ ), one of the highest reported in literature, and the cause, after extensive investigations, turned out to be undifferentiated NPC.

\section{CASE REPORT}

A 10 year female presented with backache for 1 month, nose-bleed, cough and chest pain for 1 week. Further history revealed anorexia and significant weight loss over 1 month without fever/hemoptysis/skin rashes. Past and family history were insignificant.

Examination revealed cachexia, pallor and undernutrition without organomegaly/lymphadenopathy. Vitals were within normal limits.

Labrotary Investigation of the child at admission were as shown in (Table 1).

Correspondence: $\operatorname{Dr}$ Shipra Chaudhary, Department of Pediatrics \& Adolescent Medicine, BP Koirala Institute of Health Sciences, Ghopa, Dharan, Nepal. Email: nowshipra@gmail.com, Phone: +9779842054313. 


\begin{tabular}{|c|c|c|}
\hline Investigation & Result & Normal Range \\
\hline $\begin{array}{l}\text { Hemoglobin } \\
(\mathrm{Hb})\end{array}$ & $6 \mathrm{~g} / \mathrm{dl}$ & $11-15 \mathrm{~g} / \mathrm{dl}$ \\
\hline $\begin{array}{l}\text { Total Leukocyte } \\
\text { Count (TLC) }\end{array}$ & 6800/cu mm & $\begin{array}{l}4000-11000 / \\
\text { cu mm }\end{array}$ \\
\hline Platelet & $149000 / \mathrm{cu} \mathrm{mm}$ & $\begin{array}{l}\text { 150000- } \\
400000 / \mathrm{cu} \mathrm{mm}\end{array}$ \\
\hline $\begin{array}{l}\text { Prothrombin } \\
\text { Time/INR }\end{array}$ & $18 \mathrm{sec} / 1.43$ & $13 \mathrm{sec} / 1$ \\
\hline $\begin{array}{l}\text { Erythrocyte } \\
\text { Sedimentation } \\
\text { Rate (ESR) }\end{array}$ & $60 \mathrm{~mm} / 1^{\text {st }}$ hour & $\begin{array}{l}<10 \mathrm{~mm} / 1^{\text {st }} \\
\text { hour }\end{array}$ \\
\hline Urea & 58 mg/dl & $10-50 \mathrm{mg} / \mathrm{dl}$ \\
\hline Creatinine & $0.9 \mathrm{mg} / \mathrm{dl}$ & $0.5-1.4 \mathrm{mg} / \mathrm{dl}$ \\
\hline Sodium & $135 \mathrm{mEq} / \mathrm{L}$ & $136-145 \mathrm{mEq} / \mathrm{L}$ \\
\hline Potassium & $3.8 \mathrm{mEq} / \mathrm{L}$ & $3.5-5 \mathrm{mEq} / \mathrm{L}$ \\
\hline Calcium total & 23 mg/dl & $9-11 \mathrm{mg} / \mathrm{dl}$ \\
\hline Calcium ionized & $2.08 \mathrm{mmol} / \mathrm{L}$ & $\begin{array}{l}1.05-1.27 \\
\mathrm{mmol} / \mathrm{L}\end{array}$ \\
\hline Phosphorus & $9 \mathrm{mg} / \mathrm{dl}$ & $2.0-5.1 \mathrm{mg} / \mathrm{dl}$ \\
\hline $\begin{array}{l}\text { Alkaline } \\
\text { phosphatase } \\
\text { (ALP) }\end{array}$ & $226 \mathrm{U} / \mathrm{L}$ & $130-560 \mathrm{U} / \mathrm{L}$ \\
\hline $\begin{array}{l}\text { Lactate } \\
\text { dehydrogenase } \\
\text { (LDH) }\end{array}$ & $4957 \mathrm{U} / \mathrm{L}$ & $250-450 \mathrm{U} / \mathrm{L}$ \\
\hline Serum amylase & $880 \mathrm{IU} / \mathrm{L}$ & 25-100 IU/L \\
\hline
\end{tabular}

Work-up for tuberculosis was negative. Peripheral smear showed normocytic normochromic to hypochromic picture with toxic granules. $X$ ray chest and vertebra showed prominence of bilateral hilar shadows and generalized osteopenia respectively.

After alarmingly high calcium reports, the commonest cause hyperparathyroidism was ruled out with 24hour urinary calcium $171 \mathrm{mg}$ (normal 50-300mg/24 hours) and serum parathyroid hormone (PTH) $1.2 \mathrm{pmol} / \mathrm{I}$ (normal 1.2-5.8pmol/L).

With repeated epistaxis and hematemesis on $3^{\text {rd }}$ day, meticulous examination revealed yellowish mass over right posterior nasal cavity with orbital involvement. Computed Tomography (CT) of paranasal sinuses (PNS) and orbit had findings as shown in figure 1 .

Similarly, CT thoracolumbar spine and abdomen revealed diffuse osteopenia, multiple osteolytic lesions and a well-defined hypodense lesion in right lobe of liver adjacent to inferior venacava.
Meanwhile, hypercalcemia management was started with normal saline and furosemide. Bisphosphonate zoledronic acid (4 mg over 15 minutes) was also added and calcium levels gradually decreased over next 11 days as shown in figure 2. Phosphate levels also lowered to $2.4 \mathrm{mg} / \mathrm{dl}$.

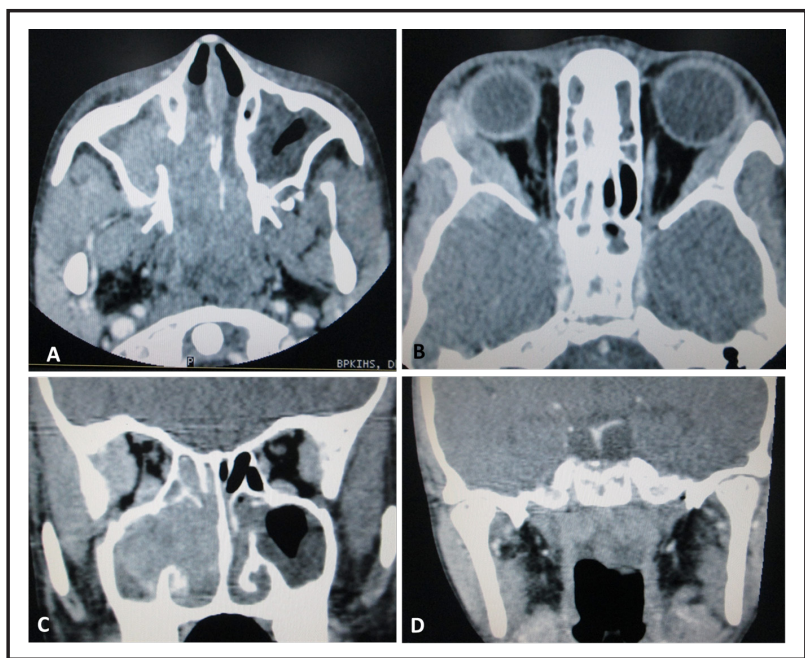

Figure 1. CECT PNS and Orbit [axial-A,B; coronal $C, D]$ shows mildly enhancing mass in right nasal cavity (extending into ipsilateral maxillary sinus, nasopharynx, posterior left nasal cavity) and extraconal space of bilateral orbit, abutting lateral rectus, middle cranial fossa and temporal fossa.

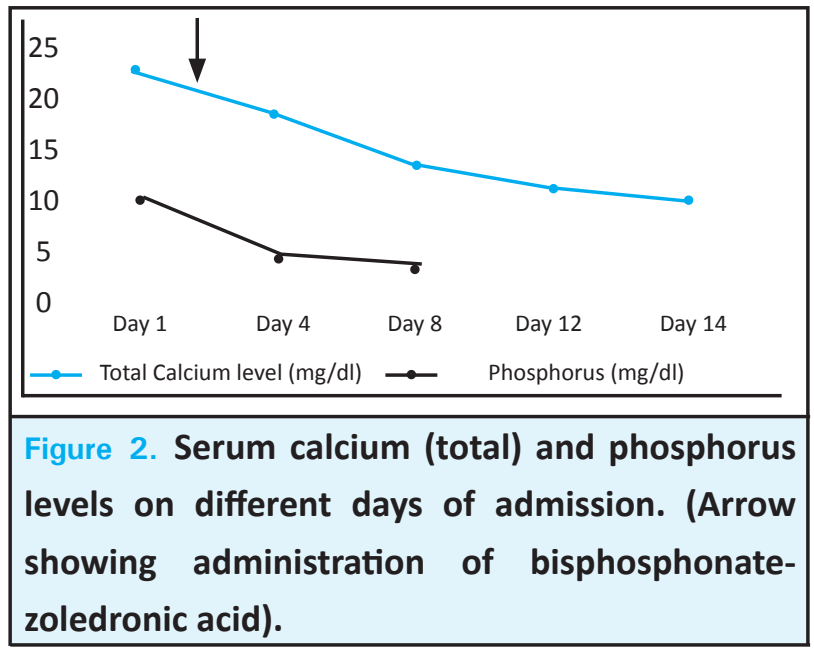

Endoscopic biopsy of the nasal mass was done and supportive measures continued but the patient developed refractory shock and died on the $15^{\text {th }}$ day. Biopsy from the nasal mass revealed undifferentiated nasopharyngeal carcinoma.

\section{DISCUSSION}

Hypercalcemia is an infrequent metabolic abnormality with 2 major causes- hyperparathyroidism and 
malignancy, requiring early differentiation for optimal management. ${ }^{1}$ Spectrum of hypercalcemia varies from asymptomatic (10-12 $\mathrm{mg} / \mathrm{dl}$ ) to hypercalcemic crisis (>14 mg/dl) with life-threatening manifestations. ${ }^{1,3}$

Although rare in developing countries and rarer $1<$ $1 / 1,000,000)$ in children, reported incidence of NPC is high in south-east Asia. ${ }^{6,7}$ Moreover, its diagnosis is often delayed due to late reporting of symptoms or hidden anatomical location of primary lesion as in our case. $^{7}$

Etiologically, NPC has been linked with oncogenic viruses, genetic and environmental factors..$^{7-9}$

Though rare and no case reports till now, hypercalcemia can be found in advanced NPC as in other solid tumors of head and neck. ${ }^{3}$ Various mechanisms are responsible for hypercalcemia in malignancy: a) humoral hypercalcemia of malignancy (HHM) because of secretion of parathyroid hormone related peptide (PTHrP) in $30-80 \%$ cases; b) direct osteolytic bone metastases in $20 \%$, c) activation of extrarenal 1- $\alpha$-hydroxylase (increased calcitriol) in $1 \%$, and d) ectopic PTH or PTH secretion by parathyroid cancer.4,5,10 PTHrP acts like PTH on renal calcium/ phosphorus metabolism and enhances synthesis of receptor activator of nuclear factor $k B$ ligand (RANKL) on osteoblasts. ${ }^{3}$ So, HHM has low PTH, high PTHrP, low phosphates, high alkaline phosphatase (ALP) and low calcitriol. In local osteolytic hypercalcemia, direct bony destruction by metastases alongwith the release of local cytokines like interleukin 1 (IL-1), IL-3, IL-6, tumor necrosis factor $\alpha$, transforming growth factor $\alpha$ and $\beta$, lymphotoxin, and $E$ series prostaglandins cause increased calcium. ${ }^{3}$ In our case, low PTH pointed towards HHM but initial high phosphates suggested local osteolytic mechanisms. Multiple mechanisms were suspected as reported in literature but the major limitation was unavailability of PTHrP and calcitriol levels. ${ }^{4,10}$

For staging, nasal mass with extension to orbit, nodes and distant metastasis suggested stage IVC. ${ }^{9}$ Morphologically, type 3 (Undifferentiated carcinoma) is most common in children and associated with advanced disease. ${ }^{10}$

Clinically there may be cervical lymphadenopathy, nasal obstruction, epistaxis, otologic, ophthalmic or neurologic manifestations. ${ }^{2,7,8}$ Prognosis depends on stage, age, gender, morphology, genetic factor etc. ${ }^{7-9}$ Radiotherapy is the mainstay of treatment. In stage IV, radiotherapy with/without adjuvant chemotherapy can reduce mortality by $18 \%$ and increase 5 -year survival by $4-6 \% .7,8$ Though planned for chemoradiation, our patient couldn't overcome ongoing complications of advanced stage.

Hypercalcemia was managed with fluids, loop diuretics and bisphosphonates. The key therapies are saline hydration (calciuresis), bisphosphonates (reduce bone resorption) and calcitonin (reduce PTH). ${ }^{3}$ Glucocorticoids can also help especially in 1,25- dihydroxyvitamin D-mediated HHM (reduce intestinal calcium absorption). ${ }^{2}$ Alternative therapies with potential benefit include like denosumab (RANKL inhibitor), gallium nitrate and hemodialysis in refractory hypercalcemia..$^{5,10}$

Thus, hypercalcemia can be a common complication in advanced tumours due to the underlying heterogeneous group of tumor-derived factors disrupting normal calcium homeostasis. Nasopharyngeal carcinoma in children is rare and hence, a high index of suspicion is required to detect it early. The concealed nasopharyngeal location brings diagnostic and therapeutic challenges. On suspicion of NPC in children, careful clinical and radiological examination must be done. Early diagnosis and timely management with supportive plus definitive measures can provide hope for better chances of survival.

\section{ACKNOWLEDGEIMENTS}

We would like to acknowledge all the faculty and staff from departments of Pediatrics, Otorhinolaryngology, Orthopedics, Ophthalmology, Radiology and Pathology from B P Koirala Institute of Health Sciences involved in the management of the patient.

\section{Conflict of Interest: None.}

Consent: JNMA Case Report Consent Form was signed by the patient and the original is attached with the patient chart.

\section{REFERENCES}

1. Carroll MF, Schade DS. A Practical Approach to Hypercalcemia. Am Fam Physician. 2003;67(9):1959-66. [pubMed]
2. Fisher MM, Misurac JM, Leiser JD, Walvoord EC. Extreme Hypercalcemia of Malignancy in a Pediatric Patient: Therapeutic Considerations. AACE Clinical Case Rep. 2015;1(1):e12-5. [Full Text] 
3. Goldner W. Cancer-Related Hypercalcemia. J Oncol Pract. 2016;12(5):426-32. [Full Text | PubMed | DOI]

4. Lim S, Han J, Park KH, Jung WJ, Lee YK, Choi A, et al. Two cases of humoral hypercalcemia of malignancy in metastatic cholangiocarcinoma. Cancer Res Treat. 2013;45(2):145-9. $[\underline{\mathrm{PMC}} \mid \underline{\mathrm{DOI}}]$

5. Clines GA. Mechanisms and treatment of hypercalcemia of malignancy. Curr Opin Endocrinol Diabetes Obes. 2011;18(6):339-46. [PubMed | DOI]

6. González-motta A, González G, Bermudéz Y, Maldonado MC, Castañeda JM, Lopéz D, et al. Pediatric Nasopharyngeal Cancer : Case Report and Review of the Literature. Cureus. 2016;8(2):e497. [ubMed | PMC | DOI]

7. Dadhich AS, Kumar N. A Child with Neck Lump and Hemicranial Pain : A Rare Case of Metastatic Nasopharyngeal Carcinoma. Oral Maxillofac Pathol J. 2014;5(2):503-5. [ Text]
8. Zamzuri Z, Adham M, A MS, Aa A, Azril M, Ar A. Nasopharyngeal Carcinoma Presented with Right Upper Limb Weakness : A Case Report. IMJM. 2012;11(2):58-61. [Full Text]

9. Casanova M, Bisogno G, Gandola L, Cecchetto G, Di Cataldo A, Basso E, et al. A prospective protocol for nasopharyngeal carcinoma in children and adolescents: The Italian Rare Tumors in Pediatric Age (TREP) project. Cancer. 2012;118(10):2718-25. [PubMed | Full Text | DOI]

10. Mirrakhimov AE. Hypercalcemia of Malignancy: An Update on Pathogenesis and Management. N Am J Med Sci. 2015;7(11):483-93. [PMC | DOI] 